\section{Formation of Condensed Tannins in Plants}

I HAVE presented evidence ${ }^{1}$ that leucoanthocyanins are probable precursors of condensed tannins; recent examination of Schinopsis spp..$^{2,3}$ supports this view (see also ref. 4). It was shown ${ }^{1}$ that most of the soluble phenolic materials in the sapwood of Eucalyptus marginata were leucoanthocyanins, and that the amount increased at the sapwood-heartwood boundary, where they were changed into the insoluble 'tannins' characteristic of this species. In some samples containing a distinctive outer heartwood zone, this change in solubility was found to be incom. plete. Monomeric leucoanthocyanins which yielded delphinidin and cyanidin were found in this zone but were not observed in the inner heartwood.

When the ray and vertical parenchyma cells die at the sapwood-heartwood boundary, increased amounts of tannins appear and are liberated into the surrounding tissues. It is significant, therefore, that the ray parenchyma cells only of Douglas fir contain leucoanthocyanins ${ }^{5}$. This conclusion was drawn from the observation that the contents of these cells rapidly became red on the addition of concentrated hydrochloric acid. However, all the leucoanthocyanins we tested failed to behave in this manner.

We have found that the leucoanthocyaning can be made insoluble if blocks of fresh wood (Eucalyptus spp.) are soaked in a mixture of 40 per cent formalin/ glacial acetic acid/water (5:15:80) under vacuum for $18 \mathrm{hr}$., heated for $1 \mathrm{hr}$., then boiled in water for $3 \mathrm{hr}$. When sections from these blocks were heated with butanol/hydrochloric acid (20:1) for $40 \mathrm{~min}$., little, or no, formation of alcohol-soluble anthocyanidins occurred. After the sections were mounted in glycerol/water/hydrochloric acid $(47: 47: 6)$ the contents of the parenchyma tissue in the sapwood were observed to be bright red; but no evidence of diffusion into the surrounding tissue was seen. Because anthocyanidins were obtained from untreated specimens, and as leucoanthocyanins are almost the only compounds which become red after heating with hydrochloric acid, the colour formed in the treated sections is considered to be due to leucoanthocyanins.

The ray cells close to the cambium were lined with leucoanthocyanins (compare with the phenolic membrane substance of Erdtman ${ }^{6}$ and the lining observed by $\left.\mathrm{Pew}^{7}\right)$. The contents of the sapwood ray cells were observed to be greater in amount at increasing distances from the cambium, assuming a clearer and brighter red colour. Only in the sapwood adjacent to the heartwood boundary did the vertical parenchyma also contain leucoanthocyanins. At the boundary and in the heartwood the fibres were red and in the case of Eucalyptus camaldulensis red inclusions were also observed. Those cells immediately surrounding kino veins in Eucalyptus obliqua were filled with leucoanthocyanins, but only small amounts were evident in the ray cells a short distance from the injury. These observations support the views of Bate-Smith and Metcalfe ${ }^{8}$ that the materials in their wood sections reacting with iron are most commonly leucoanthocyanins (see also ref. 9) formed in situ.

A marked decrease in the amount of glycosides and increase in aglycones has recently been observed after the sapwoods of Schinopsis ${ }^{2}$, Prunus ${ }^{10}$ and Eucalyptus spp. ${ }^{11}$ were changed to heartwoods. It is evident that physiological changes affect the nature of the chemical constituents. The above evidence indicates that the glycoside moieties (and probably other carbohydrates) are metabolized in the living cells of the sapwood, particularly in the region of increased activity at the heartwood boundary. Leucoanthocyanins appear to be a common product of this metabolism. Recently, it was found that the amount of $(+)$-catechin was much lower in the heartwood than in the sapwood of species which also contained leucoanthocyanins ${ }^{2}, 10.12$. Conse. quently, it seems likely that the condensed tannins in many woody plants are formed by the polymerization of leucoanthocyanins, either alone or in conjunction with catechin and other compounds.

Division of Forest Products,

W. E. Hrulis

Commonwealth Scientific and

Industrial Research Organization, Melbourne.

${ }^{1}$ Hillis, W. E., Nature, 175, 597 (1955). "Symp. Vegetable Tannins", Soc. Leather Trades Chem., $121(1956) ;$ A ust. J. Biol. Sci., 9, 263 (1956).

${ }^{2}$ King, H. G. C. , andIWhite, T., J. Soc. Leather Trades Chem., 41, 368 (1957).

${ }^{3}$ Roux, D. G., Nature, 181, 1454 (1958)

Freudenberg, K., and Weinges, K., Ann., 613, 61 (1958).

${ }^{5}$ Hancock, W. V., Forest Prod. J., ry, 335 (1957).

B Erdtman, H., Svensk Papperst., 46, 226 (1943).

? Pew, J. C., J. For., 47, 196 (1949).

${ }^{8}$ Bate-Smith, E. C., and Metcalfe, C. R., J. Linn. Soc., Lond., 55, 669 (1957).

- Gibbs, R. D., Trans. Roy. Soc. Canada, 48, 1 (1954).

${ }^{10}$ Hasegawa, M., J. Jap. For. Sac., 40, 111 (1958).

${ }^{11}$ Hillis, W. E., and Carle, A., Holzforschung (in the press).

${ }^{12}$ Hillis, W. E. (unpublished results).

\section{Electron Spin Resonance Investigations of Rat Liver and Rat Hepatoma}

STUDIES concerning the role of free-radical reactions in biological processes have long been hampered by the lack of a method for detecting free radicals in biological systems. The recent investigations of Commoner ${ }^{1}$ have shown that electron spin resonance techniques offer considerable promise for this purpose. This communication describes, first, an investigation of sample preparation and handling methods, and second, a qualitative comparison of electron spin resonance signal intensities from normal rat liver tissue with Novikoff rat hepatoma.

Measurements were carried out at 9,000 Mc./s. using a magnetic field of 3,200 gauss. The $g$ values observed were almost identical with that of the free electron. The size of all samples was approximately $1.7 \mathrm{gm}$. The free radical contents were inferred from measurements reflecting the area under the absorption curve, which is proportional to the free radical content of the samples studied.

Table 1 shows that freeze-dried rat liver samples contain about five times as many free radicals per unit weight of living tissue as samples chilled to $-196^{\circ} \mathrm{C}$. instantly upon excision of the liver and examined in the electron spin resonance spectrometer without allowing the sample temperature to exceed $-130^{\circ} \mathrm{C}$. at any time. Since the electron spin resonance line width of freeze-dried samples was found to be less than that of the instant-frozen samples, it is possible that the free radicals created during the freeze-drying process are artefacts, completely different from those originally present in frozen, but otherwise unaltered, material. This conclusion is supported by the fact that Miyagawa and Gordy et al. ${ }^{2}$ have found that the electron spin 